\title{
Comets and the Origin of Life
}


This page intentionally left blank 


\section{Comets and the Origin of Life}

\section{Janaki Wickramasinghe \\ Chandra Wickramasinghe William Mapier}

Cardiff University, UK 
Published by

World Scientific Publishing Co. Pte. Ltd.

5 Toh Tuck Link, Singapore 596224

USA office: 27 Warren Street, Suite 401-402, Hackensack, NJ 07601

UK office: 57 Shelton Street, Covent Garden, London WC2H 9HE

\section{British Library Cataloguing-in-Publication Data}

A catalogue record for this book is available from the British Library.

\section{COMETS AND THE ORIGIN OF LIFE}

Copyright (C) 2010 by World Scientific Publishing Co. Pte. Ltd.

All rights reserved. This book, or parts thereof, may not be reproduced in any form or by any means, electronic or mechanical, including photocopying, recording or any information storage and retrieval system now known or to be invented, without written permission from the Publisher.

For photocopying of material in this volume, please pay a copying fee through the Copyright Clearance Center, Inc., 222 Rosewood Drive, Danvers, MA 01923, USA. In this case permission to photocopy is not required from the publisher.

ISBN-13 978-981-256-635-5

ISBN-10 981-256-635-X

Printed in Singapore. 


\section{Preface}

The contemporary scientific approach to the origin of life is being shaped within the emergent discipline of astrobiology which combines the sciences of astronomy and biology. The widespread distribution of water and complex organic molecules in the universe is leading scientists towards a possibly erroneous point of view that life is not only present everywhere but that it is readily generated in situ from non-living matter. The idea that water and organics under the right physical conditions lead easily to life has no empirical basis at the present time, nor indeed do we have any definite knowledge of how such a transition occurs. On the other hand, empirical science is now in a position to address the question of whether life can be transferred from one astronomical setting to another.

The search for exosolar planets, life on Mars and elsewhere in the solar system, and dynamical studies of how particulate material can be transferred between potentially habitable cosmic sites, all have a bearing on the question of our origins. We argue in this book that the production of life in the first instance might be an exceedingly rare event but that its subsequent evolution and dispersal are a cosmic inevitability.

The astronomical origin of the 'stuff of life' at the level of atoms is beyond dispute. The chemical elements that make up living systems were unquestionably synthesised from the most common element hydrogen in nuclear reactions that take place in the interiors of stars. Supernova explosions scatter these atoms into interstellar clouds, and new stars and planets form from this material. The combination of atoms into organic molecules can proceed in interstellar clouds via well-attested chemical pathways, but only to a limited level of complexity that falls 
well short of life. The discovery of biochemical molecules in space material, including in meteorites, arguably crosses this threshold.

In the view of the authors of this book, the interpretation of interstellar organic molecules as the combined product of abiotic synthesis and biological detritus is an emerging paradigm. Inorganic processes can scarcely be expected to compete with biology in the ability to synthesise biochemicals, and if biology is readily distributed on an astronomical scale, its detritus must contribute to the stuff between the stars.

The Aristotelian notion that life could arise readily from everyday materials - fireflies from morning dew - came to be known as the doctrine of spontaneous generation and this doctrine dominated science well into the 19th century. When Louis Pasteur challenged this ancient idea by showing that microbes always arose from pre-existing microbes, the case for panspermia emerged. For if life always derives from preexisting life, then the possibility must be considered that it predates the Earth. This was the chain of logic followed by Lord Kelvin amongst others in the closing decades of the 19th century.

When Fred Hoyle and one of the present authors re-examined such arguments in the 1970s we turned to comets as the most likely astronomical objects that were relevant to panspermia. In the past three decades considerable progress has been made in geochemistry, microbiology and cometary studies, all of which place comets in the forefront of studies relevant to the origin of life. The basic structure of the present book started as the $\mathrm{PhD}$ thesis of the principal author with additional reviews and discussions that bring the whole story up-to-date. Several astrobiology texts have been published over the past decades, but they have been woefully short in their treatment of cometary panspermia. The present book is intended to fill this gap.

We are grateful to the Astrobiology Research Trust and to Brig Klyce for their unstinting support of our research into panspermia.

J.T. Wickramasinghe N.C. Wickramasinghe W.M. Napier 


\section{Contents}

Preface $\quad$ V

1. Overview 1

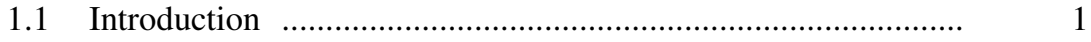

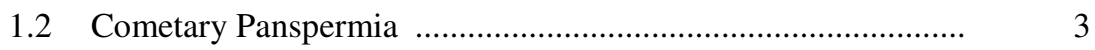

1.3 History of Panspermia ...................................................... 5

1.4 The Ultraviolet Problem ....................................................... 8

1.5 Resilience of Bacteria ..................................................... 9

1.6 Extremophiles .............................................................. 10

1.7 The Discovery of Organics in Cosmic Dust ......................... 11

1.8 Comets ............................................................................. 13

1.9 The Origin of Life ........................................................ 14

1.10 Modern Advances ............................................................... 15

1.11 Protoplanetary Nebulae and Extra-solar Planetary Systems ..... 16

1.12 Habitable Zone ............................................................ 20

2. Cosmic Dust and Life $\quad 23$

2.1 Introduction ..................................................................... 23

2.2 Constraints on Composition .............................................. 25

2.3 Extinction by Spherical Particles ....................................... 27

2.4 The Interstellar Extinction and Bacterial Dust ........................ 29

2.5 Infrared Evidence .......................................................... 37

2.6 Comet Dust and Biomaterial ............................................... 40

2.7 The Identification of PAH and Biological Aromatics .............. 43

2.8 Other Spectral Features .................................................. 48

2.9 Fluorescence .................................................................. 50

2.10 The Origin of Organic Molecules in Space ............................ 53

2.11 Direct Analysis of Comet Dust ......................................... 56

2.12 Capture of Comet Dust in the Stratosphere ............................ 58 
3. The Origin of Comets $\quad 63$

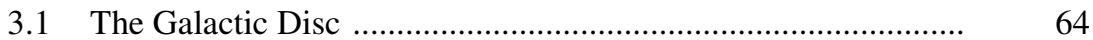

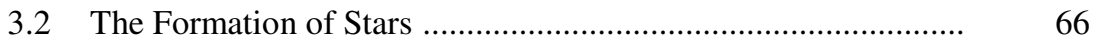

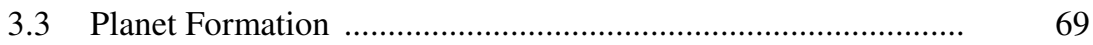

3.4 The Formation of Comets ........................................................

3.4.1 The structure of the comet population ............................. 71

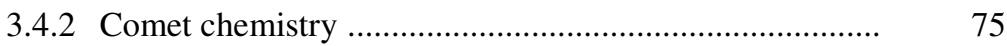

3.4.3 Cometary origin inferred ............................................. $\quad 76$

3.4.4 Other ideas about comet origins ................................... $\quad 79$

4. Comets in the Galactic Environment 81

4.1 The Mechanism of Lithopanspermia ……................................ 81

4.1.1 Transferring boulders between planetary systems ........... $\quad 82$

4.1.2 Erosion of ejected boulders ............................................. 83

4.2 The Formation Sites of Comets ................................................. 86

4.2.1 Origin in the planetary region ....................................... 87

4.2.2 Origin in molecular clouds .......................................... $\quad 90$

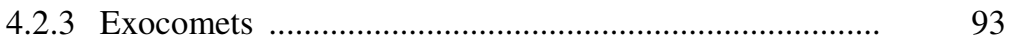

4.3 The Sun's Orbit in the Galaxy ....................................................

4.3.1 The effect of the vertical Galactic tide .......................... 95

4.3.2 Flux modulation due to the Sun's vertical motion........... $\quad 97$

4.3.3 Perturbations by molecular clouds ….............................. 100

4.3.4 The effect on Oort cloud comets …................................ 101

4.4 The Impact Cratering Record ................................................ 105

4.4.1 Impact melts in large craters .......................................... 109

4.4.2 Galactic periodicity ................................................... 111

5. Dark Comets: A Link to Panspermia …................................................ 117

5.1 A Mass Balance Problem ......................................................... 118

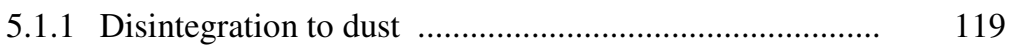

5.1.2 Dark comets ............................................................. 129

5.1.3 Super-dark comets ...................................................... 130

5.2 The Impact Hazard and the Panspermia Connection ................. 134

6. Expulsion of Microbes from the Solar System 137

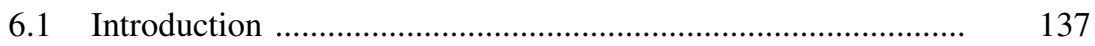

6.2 Expectations from Impact Cratering Mechanisms .................... 137

6.3 Mechanisms for Ejection and Fragmentation of Boulders ........ 140 


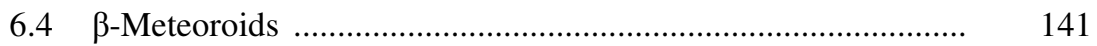

6.5 Protective Shielding in Small $\beta$-Meteoroids ............................. 142

6.6 Carbonisation of the Surface Layers of Grains ......................... 143

6.7 Radiation Pressure Effects ...................................................... 144

6.7.1 Ratio of radiation pressure to gravity .............................. 145

6.7.2 Results and dynamical considerations ........................... 147

6.8 Surviving the Hazards of Galactic Cosmic Rays ...................... 148

6.9 How Comets Distribute Life ……………................................ 153

6.10 Dispersal of Life by Impacts ……………............................. 154

7. Liquid Water in Comets 157

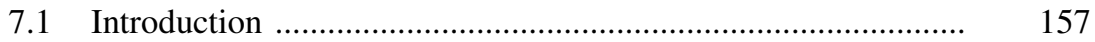

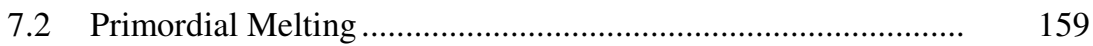

7.3 Evidence of Present-day Melting ................................................ 163

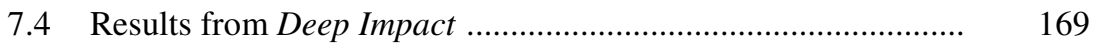

7.5 Frozen Lake Surfaces ............................................................... 178

7.6 Microbial Fossils in Carbonaceous Meteorites .......................... 180

8. Origin of Life 183

8.1 Preamble183

8.2 Cometary Interiors as Incubators of Early Life ......................... 188

8.3 Comparison with a Terrestrial Origin of Life ............................. 189

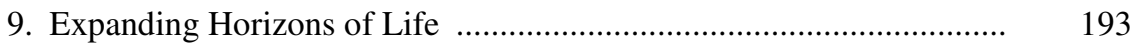

Bibliography ........................................................................... 201

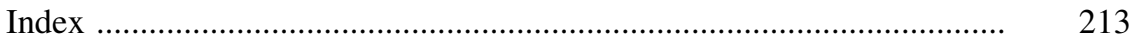

